\title{
Power Optimization and Prioritization in an Island Supplied by a Rotating Machine Based Distributed Generator Using Artificial Bee Colony Algorithm
}

\author{
L. Mogaka ${ }^{1}$, D. K. Murage ${ }^{2}$, M. J. Saulo ${ }^{1}$ \\ ${ }^{1}$ Electrical and Electronics Department, Technical University of Mombasa, Mombasa, Kenya \\ ${ }^{2}$ Electrical and Electronics Department, Jomo Kenyatta University of Agriculture and Technology, Nairobi, Kenya
}

Email address:

mogakaLucas@tum.ac.ke (L. Mogaka),dkmurage25@yahoo.com (D. K. Murage), michaelsaulo@tum.ac.ke (M. J. Saulo)

To cite this article:

L. Mogaka, D. K. Murage, M. J. Saulo. Power Optimization and Prioritization in an Island Supplied by a Rotating Machine Based Distributed Generator Using Artificial Bee Colony Algorithm. International Journal of Energy and Power Engineering. Vol. 5, No. 1, 2016, pp. 15-21. doi: 10.11648/j.ijepe.20160501.13

\begin{abstract}
Currently the greatest threat to the power systems reliability and security is the cascading of electric system failures thus causing power blackouts. For quite some time now, the world has been encountering many power blackouts as a result of these cascading failures. The cascading power failure instances pose great risks towards the integrity of power system network. This may finally lead to the splitting of the power system into various small unintentional islands. Hence, intentional or controlled islanding is then utilized as a preventive measure to mitigate the losses caused by unintentional islanding of the power system. Thus, by doing this, the entire power system is split into controlled island regions for the purposes of easy handling and control. In such situation, each islanded region should have sufficient generation to supply its connected loads in order to remain operative and stable. It should also be pointed out that intentional islanding is very important as it can prevent the entire power system from collapsing. The distributed generators supplying the loads in these islands may not be able to maintain the voltage and frequency within desired limits in the distribution system when it is islanded within the micro grid. There may be a power deficit within the island. This eventually leads to shedding of some loads within the island for the sake of stability of the system. Hence the main challenge here is to determine the appropriate and reliable method to optimize the power supply and the load demand in the island and thus maintain the voltage and frequency within the desired limit. In this study we focused on the determination of the minimum load amount for shedding within the islanded region and the prioritization of the buses for shedding so that electricity supply to customers could be maximized using $\mathrm{ABC}$ algorithm. From the results obtained, the $\mathrm{ABC}$ algorithm can be successfully applied for solving the optimization and prioritization problems within the island being supplied by a DG. The $\mathrm{ABC}$ algorithm has several merits over other algorithms which makes it suitable in this application. These advantages include; it is easily implemented, flexible, has few control parameters, easily hybridized with other optimization algorithms and can be modified very easily to suit any application. This system was simulated in MATLAB and SIMULINK using IEEE fourteen bus systems.
\end{abstract}

Keywords: ABC Algorithm, Islanding, Power Prioritization and Optimization

\section{Introduction}

An electric rotating machine can be defined as any form of apparatus which has a rotating member and generates, converts, transforms, or modifies electric power. Examples of these machines include motors and synchronous generators (SDGs). There are many types of rotating machines. The two basic and common rotating machine types are synchronous and induction generators [1].
Usually, the classical view of the power systems is characterized by a unidirectional flow of the power from one central generating point to the consumers through transmission and distribution systems. In this system, there is usually minimal amount of intelligent and automation functions involved. However, the ongoing deregulation of the power system that has given a new face to the power system by introducing the distributed generations (DGs) into distribution systems, leading to the bi-directional electric power flow. 
There is also a current trend in the continued and increasing use of Distributed Generation (DG) in the distribution systems of the power grid to supplement the mains supply due to energy exhaustion and recent environmental issues [2]. This practice enables the collection of electrical energy from a variety of sources thus leading to the decreased environmental impacts and improved security of supply. These distributed generators are typically in the range of $1-10,000 \mathrm{~kW}$ and include wind farms, micro hydro turbines, photovoltaic (PV) system and other small generators which are supplied with biomass or geothermal fuel [3].

This continued and increased integration of DGs in the power system is due to its many advantages. These include: improved system reliability in the power supply, increased efficiency, avoidance of transmission capacity upgrades, improved power quality and reduced transmission line losses and environmental benefits (excluding diesel reciprocating engines often used as back-up distributed generators which tend to be the worst performers in terms of greenhouse gas emissions [4]) [1].

On the other hand, the incorporation of these DGs in the distribution system has one major drawback; unintentional islanding. An islanding condition occurs when the distributed generator continues to power a section of the grid system even after the connection to the rest of the system has been lost, either intentionally or unintentionally.

The unintentional islanding mode of operation is not desirable because of a number of reasons as it is stipulated by the IEEE standard 1547-2003 [5]. These include and not limited to the following; it poses a threat to the line workers' safety, the islanded system may not be properly grounded resulting in high voltage in the other phases when an earth fault occurs, and most importantly, the distributed generators may not be able to maintain the voltage and frequency within desired limits in the distribution system when it is islanded [2]. That is why it becomes necessary to determine the minimum load amount for shedding within the islanded region and the prioritization of the buses for shedding so that electricity supply to customers could be maximized using $\mathrm{ABC}$ algorithm.

The rest of the paper is organized as follows; section 2 discusses the concept of the artificial bee colony algorithm and its relevance in this study, then the methodology used to achieve the study objectives is highlighted in 3 . The study results and discussions are elaborated in section 4 and the last section, 5, gives the conclusions that are drawn from the results of the study.

\section{The Artificial Bee Colony Algorithm}

\subsection{The Nature of Bees}

The Swarm Intelligence (SI) is a branch of Artificial Intelligence (AI) that has its basis on the collective characteristics of animals or certain unique phenomenon of natural setups such as bees, fish, ants and birds. In the process of searching for the food sources, the bee colony can move in several directions and over a distance of several kilometers.
This exercise of searching for new food sources commences by sending out a group of scout bees to search for flower patches at various bushes that contain a considerable amount of nectar and pollen. After this, the scout bees come back to their hive and then perform a special movement as others observe.

This dance is known as the waggle dance. This is shown in figure 1 . This waggle dance is used by the employed bees to communicate to other bees in the hive to report three main types of information. This is with regards to the availability of flower patches, which are the direction of food sources location, their quality, quantity and distances from these food sources [6].

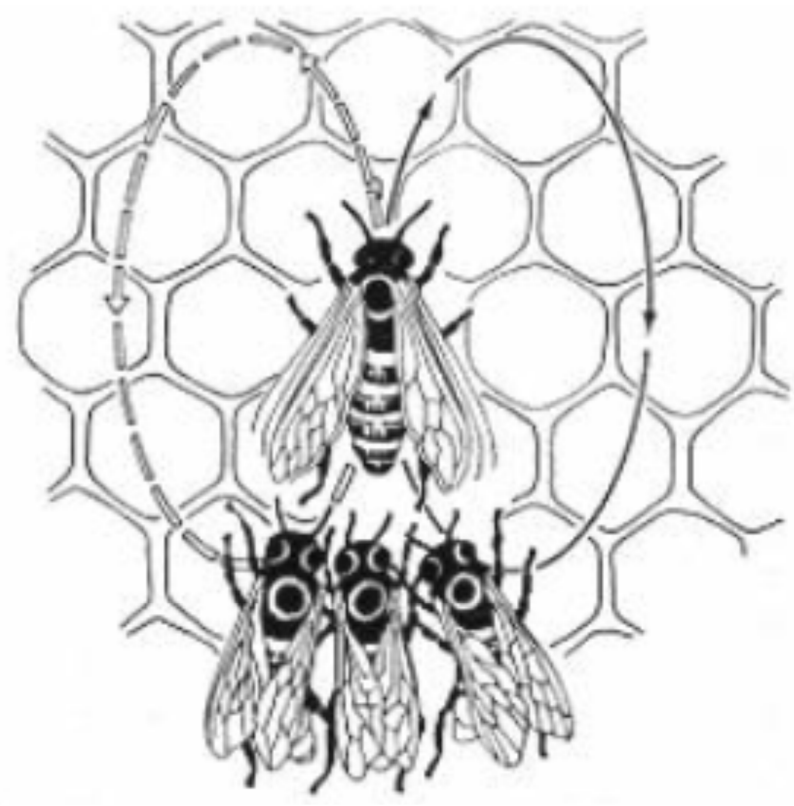

Figure 1. The bees waggle dance.

This information conveyed helps the other bees in the hive to travel towards the discovered flower patches more easily and precisely without the assistance from other bees. After the waggle dance, scout bees will fly back to the flower patches again with follower bees or worker bees [7].

The artificial bee colony algorithm consists of three important components in its operation. That includes the employed bees, unemployed foraging bees, and food sources.

- Employed bees: An employed artificial bee is often employed at one certain food source at a time which she exploits. She carries all important information about this particular food source and shares it with the rest of the bees waiting in the hive. Among other information she shares include the distance of the food source from the hive, its direction and how profitable it is.

- Unemployed bees: The group of forager bees that are looking for food sources to exploit are called unemployed bees. They can be either scout bees that search around the environment randomly or onlooker bees who try to find food sources by using the information given by the employed bees. The mean number of scouts is about percent. 
- Food Sources: An artificial bee analyses a number of factors concerning a given food source before selecting that food source. These factors include the closeness of the food source to the hive, richness and quality of the energy, taste of its nectar, and the ease or difficulty of extracting this food from the source.

In short, the artificial foraging bees consist of a group of employed bees, onlookers and scout bees. Half of this colony comprise of the employed bees which forms the majority.

Every food source has an employed bee associated with it. Once a food source is depleted, the employed bee automatically becomes a scout. Thus the amount of nectar in a batch of flowers determines the fitness value of that solution, in this case the food position.

The basic mechanism search of $\mathrm{ABC}$ is well presented in figure 2 [8] where a) Initial situation, b) Final situation.

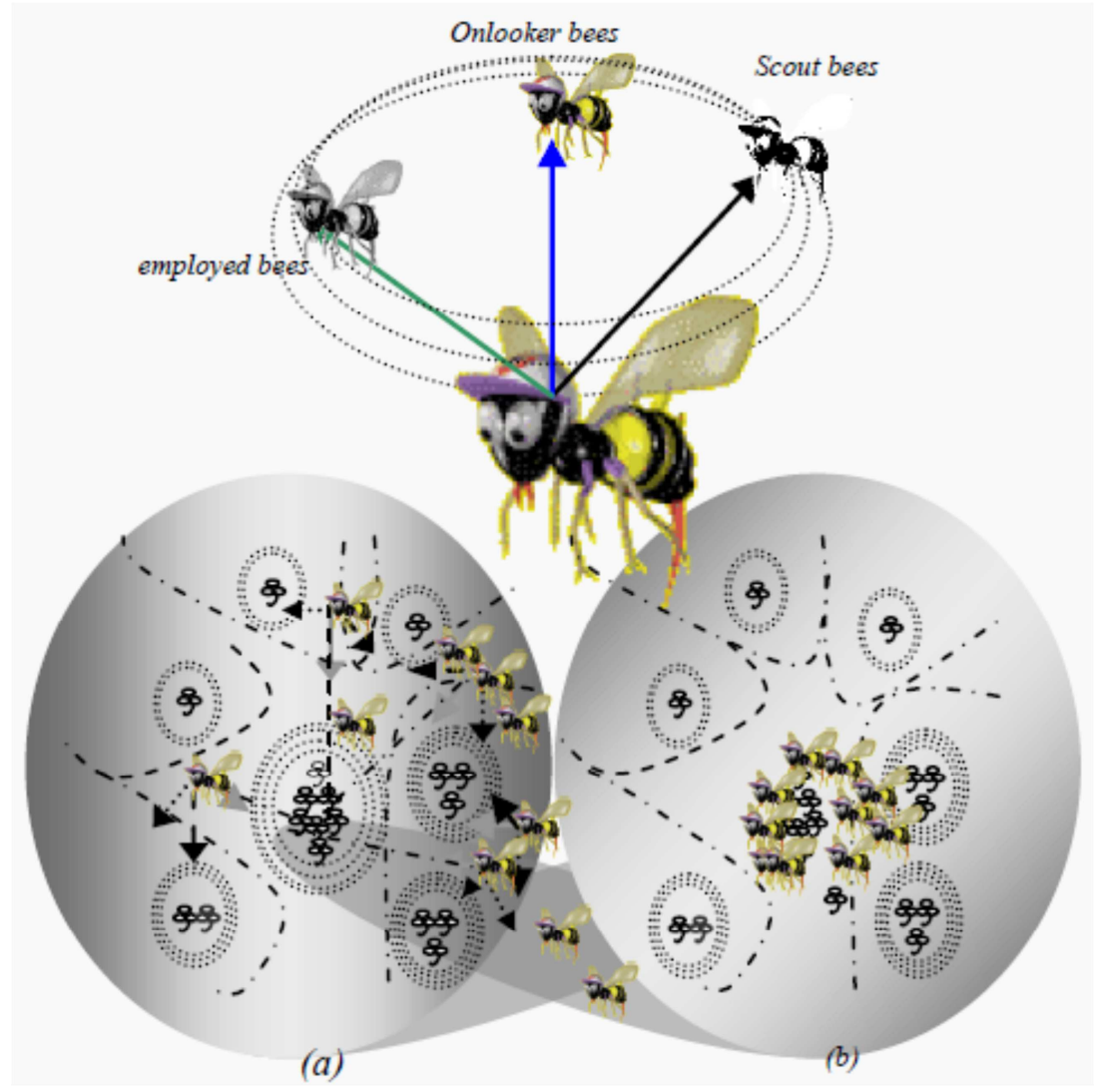

Figure 2. Basic mechanism search of $A B C$.

In the initialization stage of the $\mathrm{ABC}$ algorithm, it creates a randomly distributed initial population of solutions $(f=1,2 \ldots$ $E_{b}$ ), where $f$ signifies the size of population and $E_{b}$ is the number of employed bees [9]. Each solution of the expression $x_{f}$ is a $D$ dimensional size vector, where $D$ is the optimization parameters number. Throughout the optimization process, the artificial bees will memorize the new food position, that is, the modified solution, if the quantity of the new nectar position is higher than the previous nectar position.

Upon completion of each of the search process, the bees then share the nectar information they have found with onlooker bees in the beehive dance area. The onlooker bee will carefully observe these waggle dances and evaluate the information being conveyed and choose the food source with highest nectar quantity. The onlooker bees evaluate the nectar information and choose a food source depending on the probability value associated with that food source using the equation 1 below [10];

$$
P_{i}=\frac{f i t_{i}}{\sum_{j=1}^{n e} f i t_{i}}
$$

Where $f i t_{i}$ is the solution's fitness value $i$, which in turn is proportional to the amount of nectar of the source of food in the position $i$ and $n_{e}$ is the number of food sources which is equal to the number of employed bees in the colony [11].

On their turn, the onlooker bees also employ the same process of modification and selection of the food positions as the employed bees do. This can be demonstrated by the equation 2 below.

$$
V_{i j}=X_{i j}+Q_{i j}\left(X_{i j}-X_{k j}\right)
$$

Where $k \in\left(1,2 \ldots n_{e}\right)$ and $k \in(1,2 \ldots D)$ are selected randomly. Although $k$ is determined stochastically, it should not be equal to the value of $i . Q_{i j}$ is a random number which should be between -1 and, +1 . This controls the generation of the neighborhood food sources.

Once the new food position is determined as shown above, another cycle of the $\mathrm{ABC}$ algorithm begins. The same procedures are continuously repeated until the stopping criterion is met [9]. In nutshell, the ABC algorithm is a cycle which involve the following steps which are repeated until the 
stopping criteria is achieved [12];

Initialization Phase.

REPEAT

- Employed foragers Phase

- Onlooker foragers Phase
- Scout foragers Phase

- Memorization of the best food solution achieved

UNTIL (Cycle $=$ Maximum number of Cycles)

Generally the $\mathrm{ABC}$ algorithm steps can be summarized as shown in figure 3 [13]:

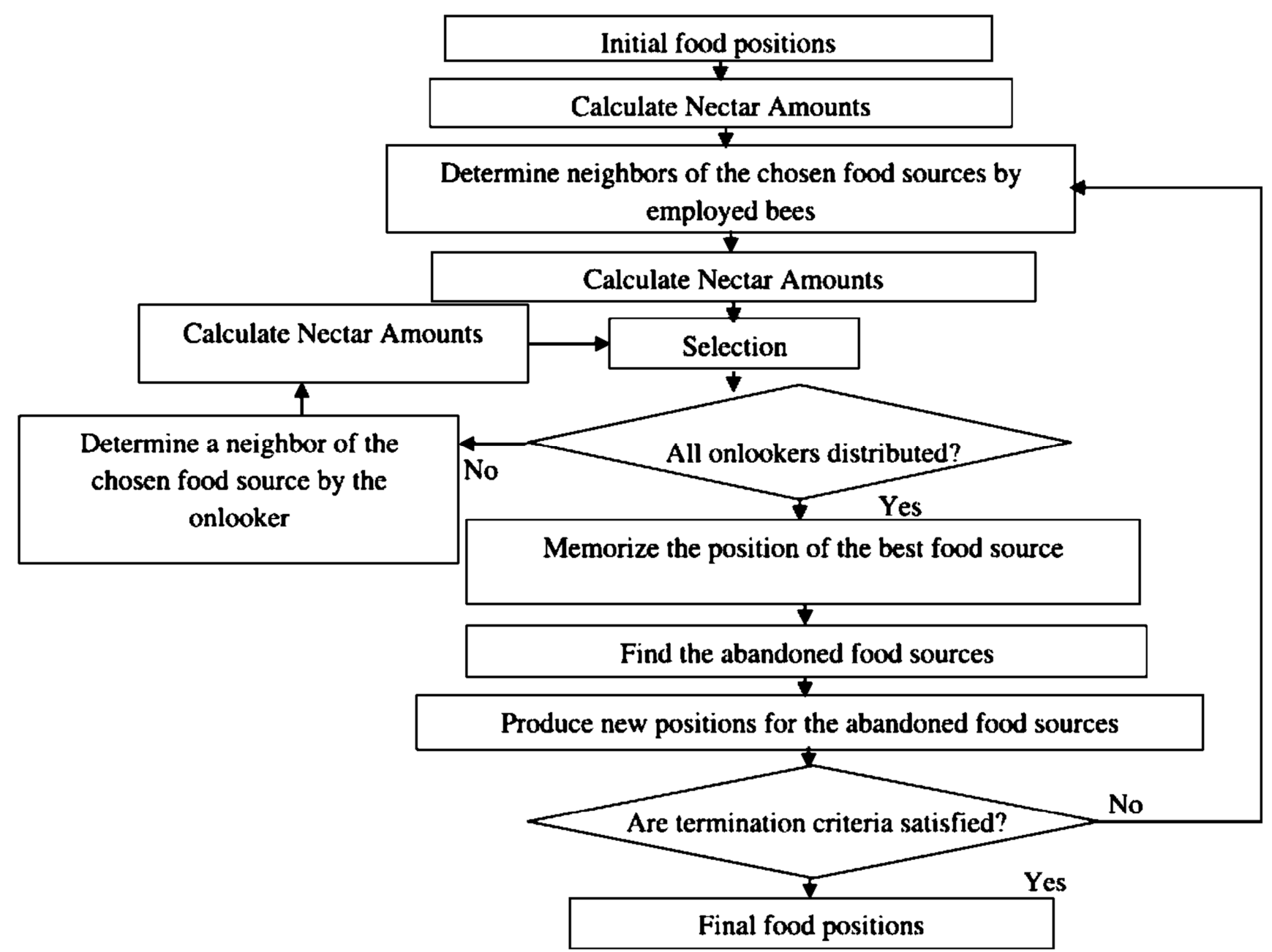

Figure 3. Artificial Bee Colony Algorithm flow chart.

\subsection{Advantages of ABC Algorithm}

The artificial bee colony algorithm system combines both the local search which is carried out by the employed and onlooker groups of bees, and also the global search which is managed by the onlookers and scout group of bees which attempts to balance the exploration and exploitation process [14]. The main advantages of the $\mathrm{ABC}$ algorithm over other optimization methods for solving optimization are [15] [16] [17] [18]:

- It is simple to deploy

- It has few control parameters

- It is robust

- It is highly flexible

- Its ease of combination with other methods

- Its ability to handle the objective with stochastic nature

- Its fast convergence as it combines both exploration and exploitation processes.

\subsection{Disadvantages of Artificial Bee Colony Algorithm}

The artificial bee colony algorithm has some few weakness when it is put into practice.

- First this method requires new fitness tests on every new algorithm parameters so as to improve its performance

- It needs a high number of objective function evaluations

- It slows down when used in sequential processing and the population of solutions increases the computational cost due to slowdown

- It has many iterations and thus huge memory capacity required.

\section{Methodology}

The major aim of this study was to determine the minimum load amount for shedding within the islanded region so that we can maximize the electricity supply to customers in case the 
load surpasses the supply within that island.

To achieve this, artificial bee colony (ABC) algorithm was used to ensure there is optimum power supply and also perform power prioritization to determine the buses to be shed based on their priority index.

The IEEE fourteen bus was used in the analysis but with little modification on the bus data and line data. To start with, the distributed generator of $320 \mathrm{~W}$ was connected at bus number two and a number of loads connected at different buses totaling to $362 \mathrm{~W}$. Then these parameters were varied separately while keeping the other constant and observations made.

The control parameters of $\mathrm{ABC}$ algorithm are assumed as follows:

- The number of colony size (employed bees and onlooker bees) is assumed to be 20 .

- The number of food sources equals the half of the colony size.

- The limit is assumed to be 100. A food source which could not be improved through limit trials is abandoned by its employed bee.

- The number of cycles for foraging is assumed to be 100 .

\subsection{System Flow Chart}

First, the frequency signals are sampled from the power line. In this study, current signals only were sampled and used in the analysis. Then features to be used in islanding detection were extracted by the use of discrete wavelet transform and the classification was done using fuzzy logic as either islanded or not islanded. In case of islanded condition, power optimization and prioritization within the island using $\mathrm{ABC}$ algorithm. Generally the system flow chart as shown in figure 4.

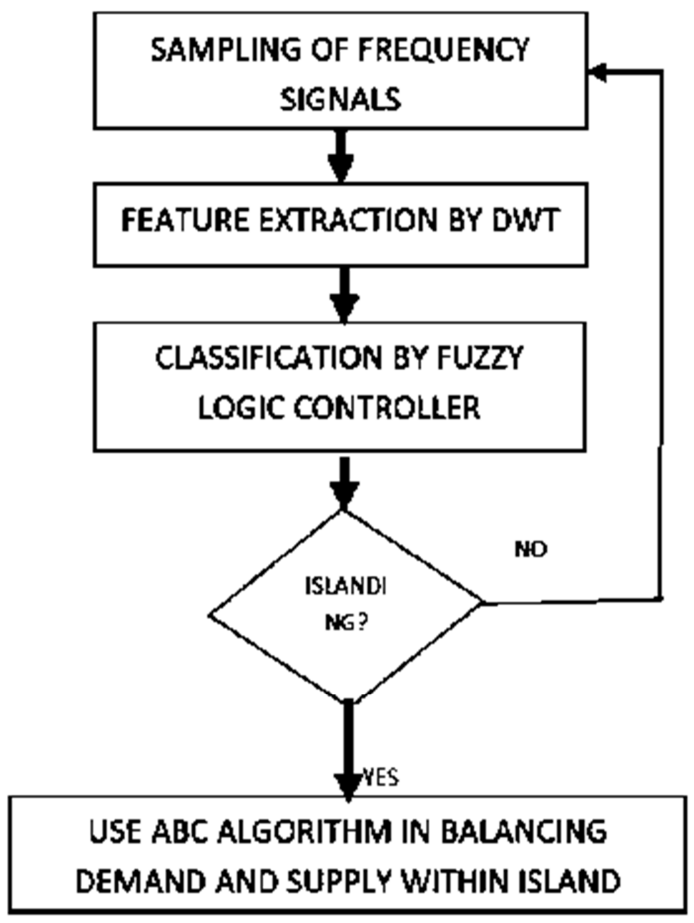

Figure 4. System flow chart.

\subsection{IEEE 14-Bus Test System}

After the occurrence of the islanding condition was successfully identified using DWT and FL, the load shedding of various buses was tested using an IEEE 14-bus test system. This system consists of five synchronous machines, including one synchronous compensator used only for reactive power support and four generators located at buses 1, 2, 6, and 8. In the system, there are twenty branches, fourteen buses and with 11 loads connected. This is shown in figure 5 below:



Figure 5. IEEE 14 bus.

The priorities for load shedding were set in the following decreasing order for Load buses 9, 10, 11, 12, 13 and 14. Out of these selected buses bus 14 is the one having highest sensitivity and therefore can be considered as the weakest bus for load shedding followed by bus 13 .

\section{Results and Discussion}

The main aim of this study involved finding the optimal load to be shed and the selection of the buses to be shed using the $\mathrm{ABC}$ algorithm. Basically there are two main strategies of load shedding. The first is based on voltage which is called Under Voltage Load Shedding (UVLS) and the other one is based on frequency known as Under Frequency Load Shedding (UFLS).

The main objective of load shedding is to provide smooth load relief, in situations where the power system would otherwise go unstable. The buses for load shedding are selected based on the priority attached to those buses and the required amount of load to be shed.

On the part of power optimization and prioritization within the islanded region, the IEEE fourteen bus was used in the 
analysis but with little modification on the bus data and line data. The distributed generator of $320 \mathrm{~W}$ was connected at bus number two and a number of loads connected at different buses totaling to $362 \mathrm{~W}$. Both the generator output and the connected load were varied and the signal variations observed.

Then using $\mathrm{ABC}$ algorithm and load flow, we were able to determine the power deficit and surplus in the island. In addition to this, the buses were given priorities and buses to be shed were picked based on the amount of deficit and the bus priority.

Table 1 is a snapshot of the system results obtained when a total of $362.5 \mathrm{~W}$ load was connected to a $320 \mathrm{~W}$ generation. From the simulation, the line losses were $32.805 \mathrm{~W}$ and the total load to be shed should be $75.305 \mathrm{~W}$ including line losses.

Table 1. Prioritization results.

\begin{tabular}{lllllll}
\hline Bus & Injection & \multicolumn{4}{l}{ Generation } & Load \\
\cline { 2 - 7 } no. & Mw & Mvar & Mw & Mvar & Mw & Mvar \\
\hline 1 & 75.305 & 0.000 & 75.305 & 0.000 & 0.000 & 0.000 \\
2 & 298.300 & 0.000 & 320.000 & 0.000 & 21.700 & 0.000 \\
3 & -94.200 & 0.000 & 0.000 & 0.000 & 94.200 & 0.000 \\
4 & -47.800 & 0.000 & 0.000 & 0.000 & 47.800 & 0.000 \\
5 & -7.600 & 0.000 & 0.000 & 0.000 & 7.600 & 0.000 \\
6 & -11.200 & 0.000 & 0.000 & 0.000 & 11.200 & 0.000 \\
7 & -0.000 & 0.000 & 0.000 & 0.000 & 0.000 & 0.000 \\
8 & 0.000 & 0.000 & 0.000 & 0.000 & 0.000 & 0.000 \\
9 & -30.000 & 0.000 & 0.000 & 0.000 & 30.000 & 0.000 \\
10 & -30.000 & 0.000 & 0.000 & 0.000 & 30.000 & 0.000 \\
11 & -30.000 & 0.000 & 0.000 & 0.000 & 30.000 & 0.000 \\
12 & -30.000 & 0.000 & 0.000 & 0.000 & 30.000 & 0.000 \\
13 & -30.000 & 0.000 & 0.000 & 0.000 & 30.000 & 0.000 \\
14 & -30.000 & 0.000 & 0.000 & 0.000 & 30.000 & 0.000 \\
Total & 32.805 & 0.000 & 395.305 & 0.000 & 362.500 & 0.000 \\
\hline
\end{tabular}

Power generated $=320.000$

Power demand $=362.500$

Losses $=32.805$

Load to shed $=75.305$

Bus to shed $=14$

\section{Constant Demand and Constant Supply Characteristics.}

The connected load was kept constant and the generator output varied and observations made. On the other hand the generator output was kept constant and the connected load varied and observations made. These are briefly shown in table 2 and 3.

Table 2. Constant demand with varying supply characteristics.

\begin{tabular}{llllll}
\hline Simulation & $\begin{array}{l}\text { Power } \\
\text { generated }\end{array}$ & $\begin{array}{l}\text { Power } \\
\text { demand }\end{array}$ & Losses & $\begin{array}{l}\text { Load to } \\
\text { shed }\end{array}$ & Shed bus \\
\hline 1 & 362.5 & 362.5 & 33.817 & - & - \\
2 & 330.0 & 362.5 & 32.983 & 65.483 & 14 \\
3 & 300.0 & 362.5 & 32.563 & 95.063 & $14 \& 13$ \\
4 & 270.0 & 365.5 & 32.486 & 124.986 & $14,13 \& 12$ \\
\hline
\end{tabular}

Table 3. Constant supply with varying demand characteristics.

\begin{tabular}{llll|l}
\hline Simulation & $\begin{array}{l}\text { Power } \\
\text { generated }\end{array}$ & Power demand & Losses & $\begin{array}{l}\text { Excess } \\
\text { generation }\end{array}$ \\
\hline 1 & 362.5 & 362.5 & 33.817 & 33.817 \\
2 & 362.5 & 352.5 & 28.568 & 18.568 \\
3 & 362.5 & 342.5 & 27.281 & 7.281 \\
4 & 362.5 & 335.5 & 26.259 & -3.741 \\
\hline
\end{tabular}

\section{Conclusion}

In this study, the $\mathrm{ABC}$ algorithm was successfully applied for solving the optimization and prioritization problems in the island being supplied by the DG. The ABC algorithm is based on the foraging behavior of honey bees for finding global and local solution for optimization problems. The advantages of using this algorithm are its robustness, fast calculation of the error, flexibility, and few parameters to be set. However, the ABC algorithm suffers a drawback of the search space limited by initial solution. In fact, this drawback can be overcome using normal distribution sample in the initial step.

This proposed algorithm has been tested on a fourteen bus system and the obtained result for this system was analyzed and it was satisfactory to draw concrete conclusions.

In comparison with other methods of optimization, the proposed algorithm can obtain better optimal solution than many other methods with a fast computational manner, especially for large-scale systems. Therefore, the proposed $\mathrm{ABC}$ algorithm can be a favorable method for solving optimization and prioritization problems in power systems.

\section{Acknowledgement}

The authors would like to express the greatest gratitude to the Technical University of Mombasa for the continued support from time to time when required.

\section{References}

[1] Azakiah, K., Hussain, S., Erdal, B., \& Tamer, K. (December 2013). A review of islanding dtection techniques for renewable distributed generation systems. Renewable and sustainable energy reviews, 28, 483-493.

[2] Belkacem, M., \& Kamel, S. (2014). Solving Practical Economic Dispatch Problems Using Improved Artificial Bee Colony Method. International Journal Intelligent Systems and Applications, 7, 36-43.

[3] F, A., Mohamed, M., Elarini, M., \& Ahmed, O. M. (2014). A new technique based on Artificial Bee Colony Algorithm for optimal sizing of stand-alone photovoltaic system. Journal of Advanced Research, 5, 397-408.

[4] Hardiansyah, Junaidi, \& Yohannes, M. (2012). Application of soft computing methods for economic load dispatch problems. International journal of computer applications, 58 (13).

[5] Hemamalini, S., \& Sishai, P. (2010). Artificial bee colony algorithm for economic dispatch problem with non-smooth cost functions, electric power components and systems. 38 (7), 786-803.

[6] Karaboga, D., \& Akay, B. (2009). A comparative study of artificial bee colony algorithm. Applied Mathematics and Computation, 214 (1), 108-132.

[7] Karaboga, D., \& Basturk, B. (2007). A powerful and efficient algorithm for numerical function optimization: artificial bee colony (ABC) algorithm. Journal of Global Optimization, 39 (3), 459-471. 
[8] Laghari, J., Mokhlis, H., Karimi, M., Bakar, A. H., \& Hasmaini, M. (2014). Computational Intelligence based techniques for islanding detection of distributed generation in distribution network: A review. Energy Conversion and Management, 88 , 139-152.

[9] Luong, D., Dieu, N., \& Pandian, V. (2013). Artificial bee colony algorithm for solving optimal power flow algorithm. The scientific world journal, 2013.

[10] Mahani, Z. A. (2000). Malaysian economic recovery measures: A response to crisis management and for long-term economic sustainability. ASEAN university network's conference on economic crisis in southeast Asia: Its social, political and cultural impacts. Bangkok, Thailand.

[11] Martin, J. (2009). Distributed vs. centralized electricity generation: are we witnessing a change of paradigm? paris.

[12] Mogaka, L. O., Murage, D. K., \& Saulo, M. J. (2015). Rotating Machine based DG islanding Detection Analysis using Wavelet Transform. International Journal of Energy and Power Engineering, 4 (5), 257-267.

[13] Mogaka, L. O., Murage, D. K., \& Saulo, M. J. (2015). Rotating Machine Based Islanding Detection Using Fuzzy Logic Method. International Journal of Energy and Power Engineering, 4 (5), 311-316.
[14] Murthy, G., Sivanagaraju, S., Satyanarayana, S., \& Rao, H. (2013). Optimal placement of DG in distribution system to mitigate power quality disturbances. World academy of science, engineering and technology, 7, 204-209.

[15] Pukar, M., Zhe, C., \& Birgitte, B. J. (2008). Review on islanding operation of distribution system with distributed generation. International Conference on Electric Utility Deregulation and Restructuring and Power Technologies. Nanjing, china.

[16] Rao, R., Narasimham, S., \& Ramalingaraju, M. (2008). Optimization of distribution network configuration for lossr eduction using artificial bee colony algorithm. International Journal of Electrical Power and Energy Systems, 1 (2), 116-122.

[17] Singh, A. (2009). An artificial bee colony algorithm for the leaf constrained minimum spanning tree problem. Applied Soft Computing Journal, 9 (2), 625-631.

[18] Sumpavakup, C., Srikun, I., \& Chusanapiputt, S. (2010). A Solution to the Optimal Power Flow Using Artificial Bee Colony Algorithm. International Conference on Power System Technology, 1-5. 